\title{
The role of BRCA1 in DNA damage response
}

\author{
Jiaxue Wu, Lin-Yu Lu, Xiaochun Yu (ه) \\ Division of Molecular Medicine and Genetics, Department of Internal Medicine, University of Michigan \\ Medical School, Ann Arbor, MI 48109, USA
}

$\triangle$ Correspondence: xiayu@umich.edu

Received October 30, 2009; accepted December 10, 2009

\begin{abstract}
BRCA1 is a well-established tumor suppressor gene, which is frequently mutated in familial breast and ovarian cancers. The gene product of BRCA1 functions in a number of cellular pathways that maintain genomic stability, including DNA damage-induced cell cycle checkpoint activation, DNA damage repair, protein ubiquitination, chromatin remodeling, as well as transcriptional regulation and apoptosis. In this review, we discuss recent advances regarding our understanding of the role of BRCA1 in tumor suppression and DNA damage response, including DNA damage-induced cell cycle checkpoint activation and DNA damage repair.
\end{abstract}

\section{KEYWORDS BRCA1, DNA damage response, tumor-} igenesis

\section{INTRODUCTION}

Breast cancer is one of the most common cancers in women, accounting for over $20 \%$ of all cancer cases. Among them, $5 \%-10 \%$ of breast cancer cases are ascribed to hereditary predisposition (Alberg and Helzlsouer, 1997). Using linkage analysis, BRCA1 was identified as the first breast cancer susceptibility gene (Hall et al., 1990). Germline mutations of $B R C A 1$ have been found to predispose women to high risk of breast and ovarian cancers (Futreal et al., 1994; Brody and Biesecker, 1998; Venkitaraman, 2002). BRCA1 mutations in germline usually occur in one allele, while the other healthy allele is further mutated or lost during cancer development.

BRCA1 gene contains 24 exons that encode an 1863residue nuclear protein in human (Miki et al., 1994). The exon 11 is the largest exon and encodes over $60 \%$ of amino acids of BRCA1. Although it shares very limited homology with other known proteins, BRCA1 contains two functional domains: an N-terminal Ring domain and a C-terminal BRCT domain. Similar to other Ring domains, the Ring domain of BRCA1 has E3 ubiquitin ligase activity and facilitates protein ubiquitination (Panier and Durocher, 2009). The C-terminal BRCT domain of BRCA1 is a phospho-protein binding domain (Manke et al., 2003; Rodriguez et al., 2003; Yu et al., 2003), which is also required for BRCA1's translocation and accumulation at DNA damage sites (discussed later). Although mutations in BRCA1 are scattered throughout the gene body, many cancer-associated mutations have been found within the Ring domain and the BRCT domain of BRCA1, indicating that both domains are very important to suppress breast and ovarian cancer formation (Monteiro et al., 1996; Brzovic et al., 2001; Williams and Glover, 2003).

Since the discovery of BRCA1 gene, several genetically engineered mouse models have been created for studying the role of BRCA1 in vivo. Until now, at least nine different conventional BRCA1 knockout mouse strains have been generated and characterized. Each strain carries a mutation in different part of BRCA1 to generate null allele (Evers and Jonkers, 2006; Bouwman and Jonkers, 2008). Deletion of $B R C A 1$ in mice was embryonic lethal, which was accompanied by growth retardation, apoptosis, cell cycle defects and genomic instability, suggesting that BRCA1 is essential for early embryonic development (Deng, 2002). Unlike that in human, the spontaneous tumor penetrance in $B R C A 1^{+/-}$mice was similar to that in wild-type mice, mainly because the wildtype BRCA1 allele was rarely affected during the short life span of mouse. However, with low-dose ionizing radiation (IR) treatment, $B R C A 1$ heterozygous mice were prone to ovarian cancer, suggesting that this animal model could be very useful to analyze the mechanism of ovarian tumorigenesis (Jeng et al., 2007). In addition, conditional BRCA1 knockout 
mice have been generated by Cre recombinase-mediated deletion of genomic regions flanked by loxP recombination site in special tissues. Up to date, at least five different conditional BRCA1 knockout mouse strains have been generated (Xu et al., 1999; Mak et al., 2000; Liu et al., 2007a; McCarthy et al., 2007; Shakya et al., 2008). However, mammary tumorigenesis occurred at low frequency after long latency in these conditional knockout mice, suggesting that other genetic hits may cooperate with loss of BRCA1 together to induce breast neoplasia (Liu et al., 2007a). Indeed, genetic deletion of both BRCA1 and p53 significantly accelerated breast cancer formation, suggesting the genetic interaction between BRCA1 and p53 in tumor suppression (Liu et al., 2007a).

Although the precise role of BRCA1 in breast tumor prevention remains elusive, accumulating evidence suggests that BRCA1 could be one of the key players in DNA damage response. Double-stranded DNA inside cell nucleus constantly encounters damages induced by both external and internal hazards, such as IR, UV and oxidative stress. If not correctly treated, these damages will be accumulated along with DNA replication and be passed into daughter cells. Accumulated DNA damage will cause genomic instability and finally lead to tumorigenesis. In the presence of BRCA1, cells could sense and repair DNA lesions, which ensures genomic integrity and prevents tumorigenesis, whereas cancerassociated BRCA1 mutations disrupt normal DNA damage response. Therefore, the pivotal roles of BRCA1 in DNA damage response might explain itself as an important tumor repressor. Here, we will discuss the role of BRCA1 in DNA damage response, including the molecular mechanisms by which BRCA1 is recruited to DNA damage sites and by which BRCA1 promotes DNA damage checkpoint activation and DNA damage repair.

\section{BRCA1 IS RECRUITED TO DNA DAMAGE SITES}

The most direct and obvious evidence supporting BRCA1's roles in DNA damage response is that BRCA1 relocates to DNA damage sites and forms nuclear foci following DNA double-strand breaks (DSBs) (Scully et al., 1997a). Although this phenomenon was observed more than 10 years ago, the signaling cascade that triggers BRCA1's translocation remains largely unknown until recently. Following DNA damage, chromatin-associated histone H2AX that locates close to DNA damage sites is phosphorylated by ATM and ATR (Burma et al., 2001), and subsequently recruits a phospho-module binding mediator MDC1 and an E3 ubiquitin ligase RNF8 to DNA damage sites (Stucki et al., 2005; Huen et al., 2007; Kolas et al., 2007; Mailand et al., 2007). RNF8 functions together with an E3 ubiquitin conjugase Ubc13 to ubiquitinate histone $\mathrm{H} 2 \mathrm{~A}$ and $\mathrm{H} 2 \mathrm{~B}$ at chromatin lesions, which regulates the translocation of BRCA1 to DNA damage sites (Zhao et al., 2007; Wu et al., 2009). Using protein affinity purification approaches, we and others have identified a novel BRCA1 complex recently, including BRCA1, RAP80, CCDC98/Abraxas, NBA1/MERIT40, BRCC36 and BRCC45 (Kim et al., 2007a, b; Liu et al., 2007b; Sobhian et al., 2007; Wang et al., 2007; Feng et al., 2009; Shao et al., 2009; Wang et al., 2009). Following DNA damage, RAP80 recognizes ubiqutinated histone at the site of DNA damage via its ubiquitin-interacting motif (UIM) and recruits the big complex, including BRCA1 to DNA damage sites (Wu et al., 2009).

\section{BRCA1 IS IMPORTANT FOR DNA DAMAGE- INDUCED CELL CYCLE CHECKPOINTS ACTIVATION}

Cell cycle checkpoints serve to monitor the chromatin status during cell cycle, which ensures that cell cycle proceeding normally (Hartwell and Weinert, 1989). Upon DNA damage, cell cycle checkpoints are activated to arrest cells at certain stage during cell cycle, which allow cells to have enough time to repair damaged DNA before resuming cell cycle progression (Hartwell and Kastan, 1994). The checkpoint activation following DNA damage is critical for maintaining genomic integrity as it guards against duplication of damaged DNA and passage of damaged DNA to daughter cells. Consistently, dysfunction of proteins involved in cell cycle checkpoints often results in developmental abnormality, genomic instability and tumorigenesis (Lobrich and Jeggo, 2007). According to the different stages during cell cycle where they function, cell cycle checkpoints can be categorized into $\mathrm{G} 1 / \mathrm{S}$, S-phase and G2/M checkpoints, and BRCA1 has been suggested to be responsible for all of these checkpoints activations.

\section{G1/S checkpoint}

Following DNA damage, the G1/S checkpoint arrests cells at G1/S boundary, which prevents damaged DNA in G1 cells to be used for upcoming DNA replication. The tumor suppressor p53 plays a critical role in DNA damage-induced G1/S checkpoint by controlling cyclin inhibitor p21's transcription (Kuerbitz et al., 1992; Dulic et al., 1994; Reed et al., 1994). Using siRNA to downregulate BRCA1, Fabbro et al showed that BRCA1-depleted cells had defective $\mathrm{G} 1 / \mathrm{S}$ checkpoint in response to DNA damage (Fabbro et al., 2004). They demonstrated that BRCA1 acted as a scaffold protein facilitating phosphorylation of p53 by ATM in response to DNA damage, which led to p53-mediated induction of p21 and induced G1/S arrest. In this study, they also demonstrated that although BRCA1 was required for both IR and UV-induced p53 phosphorylation by ATM/ATR, BRCA1 was only required for IR-induced G1/S checkpoint, but not for UVinduced G1/S arrest (Fabbro et al., 2004). However, a recent study indicated that primary fibroblasts from human BRCA1 heterozygotes displayed a moderate impaired $\mathrm{G} 1 / \mathrm{S}$ cell cycle 
checkpoint compared with wild-type cells after UV treatment (Shorrocks et al., 2004). Nevertheless, BRCA1 mediating ATM-dependent p53 phosphorylation demonstrates the functional interaction between these two important tumor suppressors in the G1/S checkpoint.

\section{S-phase checkpoint}

Another cell cycle checkpoint induced by DNA damage is Sphase checkpoint, which suppresses $S$ phase progression and stops DNA replication immediately following DNA damage (Larner et al., 1997). Since S-phase checkpoint is defective in BRCA1-deficient HCC1937 cells and complementation of functional BRCA1 in this cell line can restore the S-phase checkpoint following DNA damage, it demonstrates that BRCA1 plays an essential role in S-phase checkpoint activation (Xu et al., 2001). Like BRCA1, deficiency of many DNA damage response proteins, such as ATM, ATR, Chk1 and Chk2, has been shown to cause defects in DNA damageinduced S phase checkpoint (Painter, 1981; Lim et al., 2000; Falck et al., 2001; Yazdi et al., 2002). Following DNA damage, ATM and ATR are activated and stimulate Chk1 and Chk2. Activated Chk1 and Chk2 regulate a family of phosphates Cdc25 A/B/C, which governs cyclins and cyclin-dependent kinases' activity during $S$ phase progression (Zhao et al., 2002). Although the detail mechanism is not clear, BRCA1 participates in this signal transduction by regulating Chk1 kinase activity (Yarden et al., 2002). Moreover, ATM-mediated Ser1387 phosphorylation of BRCA1 is specifically required for the S-phase checkpoint following IR, suggesting that phospho-BRCA1 may recruit functional partners for regulating this signal cascade (Xu et al., 2001). In addition, BRCA1 may also regulate ATM activation following DNA damage in S phase. It has been shown that BRCA1 interacted and colocalized with Mre11/Rad50/NBS1 (MRN) complex (Zhong et al., 1999; Wu et al., 2000a), which is a sensor for DSBs and directly activates ATM (Lee and Paull, 2004, 2005).

\section{G2/M checkpoint}

Besides G1/S and S-phase checkpoint, DNA damage also activates $\mathrm{G} 2 / \mathrm{M}$ checkpoint, which transiently arrest cells at G2/M boundary. It allows cells to repair DNA lesions prior to mitosis and prevents damaged DNA being passed to daughter cells. The mechanism of $\mathrm{G} 2 / \mathrm{M}$ checkpoint has been well studied. Upon DNA damage, Chk1 and Chk2 are phosphorylated and activated by ATM and ATR. Activated Chk1 and Chk2 then phosphorylate mitotic kinase Weel and $\mathrm{Cdc} 25 \mathrm{~A} / \mathrm{B} / \mathrm{C}$, which suppress the activity of cyclin $\mathrm{B}$ and Cdc2 and block cells entering mitosis (O'Connell et al., 1997; Rhind et al., 1997; O'Connell et al., 2000; Cuddihy and O'Connell, 2003). Loss of BRCA1 abolishes this G2/M checkpoint action. Like in S-phase checkpoint activation, BRCA1 regulates Chk1 kinase activity during G2/M checkpoint activation (Yu and Chen, 2004). Distinct from in S-phase checkpoint activation, ATM phosphorylates Ser1423 of BRCA1, which is required for G2/M checkpoint activation, suggesting that BRCA1 may have different functional partners to mediate G2/M checkpoint activation analogous to S-phase checkpoint activation (Xu et al., 2001).

\section{BRCA1 PROMOTES DNA DAMAGE REPAIR}

BRCA1 was first implicated in DNA damage repair because it translocated to DNA damage sites and colocalized with RAD51, an essential protein in homologous recombination repair (Scully et al., 1996, 1997b). Later on, many studies from different groups have demonstrated that BRCA1deficient cells were hypersensitive to DNA damage agents such as IR, UV and DNA alkylating agents and impaired DNA damage repair, further suggesting that BRCA1 plays an important role in DNA repair (Scully et al., 1999).

In response to different types of DNA damage, different DNA repair processes utilize different repair machineries, including homologous recombination (HR), non-homologous end-joining (NHEJ), nucleotide excision repair (NER), base excision repair (BER) and mismatch repair (MMR) (Murakami and Kawasaki, 1975; Jeggo, 1998; Dasika et al., 1999; Harfe and Jinks-Robertson, 2000; Bernstein et al., 2002). Among them, NHEJ and HR are two predominant repair pathways for DSBs, the most deleterious damage on the chromatin. Furthermore, BRCA1 participates in both types of DNA repair.

\section{BRCA1 and NHEJ}

NHEJ is the most common form of DNA repair in cells, which mainly occurs during G1 phase. Unlike HR, which faithfully repairs damaged DNA, NHEJ is a relatively error-prone type of repair without using additional template. The DNA damage ends with limited processing are directly ligated, which results in removal or addition of bases at broken ends. BRCA1 has been implicated in the NHEJ repair pathway, although this remains contentious with numerous studies presenting conflicting results using both in vivo and in vitro assays. The most possible explanation for BRCA1 being involved in NHEJ is that BRCA binds to MRN complex both in vitro and in vivo, although the mechanism of this interaction is still unclear (Fu et al., 2003). MRN complex plays an major role in both NHEJ and HR repair (Fu et al., 2003). There is evidence that BRCA1 can suppress the nuclease activity of MRE11 and BRCA1 is required for ATM-dependent phosphorylation of NBS1 following DNA damage (Zhong et al., 1999; Wang et al., 2000; Wu et al., 2000b; Paull et al., 2001; Foray et al., 2003). In addition, many studies have provided evidence that the NHEJ pathway was defective in BRCA1-deficient MEFs, human BRCA1deficient cells HCC1937 and lymphoblastoid cells obtained from women carrying truncation or missense BRCA1 mutations using different assays (Baldeyron et al., 2002; Zhong et 
al., 2002; Bau et al., 2004; Coupier et al., 2004; Bau et al., 2006). However, these assays are either indirect or nonspecific for NHEJ. Meanwhile, previous studies have also shown conflicting results on the role of BRCA1 in NHEJ. It has been shown that BRCA1-deficient mouse ES cells were proficient in NHEJ repair and the random plasmid integration rate of BRCA1-deficient mouse ES cells was higher than that of control wild type cells (Moynahan et al., 1999; Snouwaert et al., 1999). Moreover, pulse-field gel electrophoresis displays similar DSB repair kinetics in HCC1937 and wild type BRCA1complemented HCC1937 cells, suggesting that BRCA1 is not required for NHEJ (Wang et al., 2001). To understand and explain why these observations are inconsistent, it is essential to understand the mechanisms of NHEJ repair and each assays used to detect NHEJ, as different assays may examine different repair mechanisms.

\section{BRCA1 and HR}

Unlike NHEJ, HR occurs only during S and G2 phase of the cell cycle when sister chromatids are present. HR is activated by DNA damage and relies on ATM and MRN complexmediated resection of double-stranded broken ends into single-stranded DNA (ssDNA). Then ssDNA are coated by RPA, a group of ssDNA binding proteins, forming substrates for loading the recombinase RAD51, which catalyses invasion of ssDNA into sister chromatid. Using sister chromatid as the template, ssDNA is elongated and holiday junctions are formed between two sister chromatids. The holiday junction is then resolved and DNA ends are ligated in an error-free manner (West, 2003). BRCA1 interacts with MRN complex during HR repair, indicating that BRCA1 may participate in MRN-dependent DNA end resection (Greenberg et al., 2006). In addition, recently, we and others identified that BRCA1 interacted with PALB2 and BRCA2 at DNA damage sites (Sy et al., 2009; Zhang et al., 2009a, b). Both PALB2 and BRCA2 are functional partners of RAD51 and facilitate RAD51ssDNA filament formation (Xia et al., 2006). Loss of BRCA1 disrupts the stability of PALB2 and BRCA2 at DNA damage sites, which in turn abolishes RAD51's localization at DNA lesions and abrogates HR repair (Zhang et al., 2009a, b).

Recently, accumulated evidence shows that BRCA1 and BRCA2-deficient cells are hypersensitive to Poly(ADPribose) polymerase (PARP) inhibitors, suggesting that PARP inhibitors can be employed as novel therapeutic drugs to selectively treat BRCA1 or BRCA2-deficient breast tumors (Bryant et al., 2005; Farmer et al., 2005). PARP is a key regulator in base excision repair process and participates in repair of DNA single strand breaks (SSBs) (Bouchard et al., 2003). Loss of PARP activity is likely to cause the accumulation of SSBs, which are converted to DSBs during replication or HR repair (Curtin, 2005). The increased DNA lesions result in the lethality of BRCA1 or BRCA2-deficient cells. PARP inhibitors in the recent clinical trials have shown profound antitumor activities in breast, ovarian and prostate cancers with BRCA1 or BRCA2 mutations (Fong et al., 2009). Thus, PARP1 inhibitors are likely to be promising drugs for clinical treatment of BRCA1 and BRCA2-deficient tumors (Bolderson et al., 2009).

\section{CONCLUSIONS}

We have examined evidence supporting BRCA1's important role in DNA damage response, including cell cycle checkpoint activation and DNA damage repair. Although the molecular mechanisms underlying BRCA1's roles in DNA damage response are emerging, they are far from clear, and many discrepancies still exist. Insights into the mechanisms of BRCA1 in checkpoint regulation and DNA damage repair will help us understand the molecular mechanisms by which BRCA1 maintains the genomic stability and contributes to tumor suppression in vivo, and ultimately find effective ways to prevent breast cancer development.

\section{ACKNOWLEDGEMENTS}

L.L. is a recipient of postdoctoral fellowship from Center for Genetics in Health and Medicine in University of Michigan. This work was supported in part by grants from the National Institutes of Health (CA132755 to XY) and the Developmental fund from the University of Michigan Cancer Center.

\section{ABBREVIATIONS}

BER, base excision repair; DSBs, DNA double-strand breaks; HR, homologous recombination; IR, ionizing radiation; MMR, mismatch repair; MRN complex, Mre11/Rad50/NBS1 complex; NER, nucleotide excision repair; NHEJ, non-homologous end-joining; ssDNA, singlestranded DNA; UIM, ubiquitin-interacting motif

\section{REFERENCES}

Alberg, A.J., and Helzlsouer, K.J. (1997). Epidemiology, prevention, and early detection of breast cancer. Curr Opin Oncol 9, 505-511.

Baldeyron, C., Jacquemin, E., Smith, J., Jacquemont, C., De Oliveira, I., Gad, S., Feunteun, J., Stoppa-Lyonnet, D., and Papadopoulo, D. (2002). A single mutated BRCA1 allele leads to impaired fidelity of double strand break end-joining. Oncogene 21, 1401-1410.

Bau, D.T., Fu, Y.P., Chen, S.T., Cheng, T.C., Yu, J.C., Wu, P.E., and Shen, C.Y. (2004). Breast cancer risk and the DNA double-strand break end-joining capacity of nonhomologous end-joining genes are affected by BRCA1. Cancer Res 64, 5013-5019.

Bau, D.T., Mau, Y.C., and Shen, C.Y. (2006). The role of BRCA1 in non-homologous end-joining. Cancer Lett 240, 1-8.

Bernstein, C., Bernstein, H., Payne, C.M., and Garewal, H. (2002). DNA repair/pro-apoptotic dual-role proteins in five major DNA repair pathways: fail-safe protection against carcinogenesis. Mutat Res 511, 145-178.

Bolderson, E., Richard, D.J., Zhou, B.B., and Khanna, K.K. (2009). Recent advances in cancer therapy targeting proteins involved in DNA double-strand break repair. Clin Cancer Res 15, 6314-6320. 
Bouchard, V.J., Rouleau, M., and Poirier, G.G. (2003). PARP-1, a determinant of cell survival in response to DNA damage. Exp Hematol 31, 446-454.

Bouwman, P., and Jonkers, J. (2008). Mouse models for BRCA1 associated tumorigenesis: from fundamental insights to preclinical utility. Cell Cycle 7, 2647-2653.

Brody, L.C., and Biesecker, B.B. (1998). Breast cancer susceptibility genes. BRCA1 and BRCA2. Medicine 77, 208-226.

Bryant, H.E., Schultz, N., Thomas, H.D., Parker, K.M., Flower, D., Lopez, E., Kyle, S., Meuth, M., Curtin, N.J., and Helleday, T. (2005). Specific killing of BRCA2-deficient tumours with inhibitors of poly (ADP-ribose) polymerase. Nature 434, 913-917.

Brzovic, P.S., Meza, J.E., King, M.C., and Klevit, R.E. (2001). BRCA1 RING domain cancer-predisposing mutations. Structural consequences and effects on protein-protein interactions. J Biol Chem 276, 41399-41406.

Burma, S., Chen, B.P., Murphy, M., Kurimasa, A., and Chen, D.J. (2001). ATM phosphorylates histone H2AX in response to DNA double-strand breaks. J Biol Chem 276, 42462-42467.

Coupier, I., Baldeyron, C., Rousseau, A., Mosseri, V., PagesBerhouet, S., Caux-Moncoutier, V., Papadopoulo, D., and Stoppa-Lyonnet, D. (2004). Fidelity of DNA double-strand break repair in heterozygous cell lines harbouring BRCA1 missense mutations. Oncogene 23, 914-919.

Cuddihy, A.R., and O'Connell, M.J. (2003). Cell-cycle responses to DNA damage in G2. Int Rev Cytol 222, 99-140.

Curtin, N.J. (2005). PARP inhibitors for cancer therapy. Expert Rev Mol Med 7, 1-20.

Dasika, G.K., Lin, S.C., Zhao, S., Sung, P., Tomkinson, A., and Lee, E. Y. (1999). DNA damage-induced cell cycle checkpoints and DNA strand break repair in development and tumorigenesis. Oncogene 18, 7883-7899.

Deng, C.X. (2002). Tumor formation in Brca1 conditional mutant mice. Environ Mol Mutagen 39, 171-177.

Dulic, V., Kaufmann, W.K., Wilson, S.J., TIsty, T.D., Lees, E., Harper, J.W., Elledge, S.J., and Reed, S.I. (1994). p53-dependent inhibition of cyclin-dependent kinase activities in human fibroblasts during radiation-induced G1 arrest. Cell 76, 1013-1023.

Evers, B., and Jonkers, J. (2006). Mouse models of BRCA1 and BRCA2 deficiency: past lessons, current understanding and future prospects. Oncogene 25, 5885-5897.

Fabbro, M., Savage, K., Hobson, K., Deans, A.J., Powell, S.N., McArthur, G.A., and Khanna, K.K. (2004). BRCA1-BARD1 complexes are required for p53Ser-15 phosphorylation and a G1/S arrest following ionizing radiation-induced DNA damage. J Biol Chem 279, 31251-31258.

Falck, J., Mailand, N., Syljuasen, R.G., Bartek, J., and Lukas, J. (2001). The ATM-Chk2-Cdc25A checkpoint pathway guards against radioresistant DNA synthesis. Nature 410, 842-847.

Farmer, H., McCabe, N., Lord, C.J., Tutt, A.N., Johnson, D.A., Richardson, T.B., Santarosa, M., Dillon, K.J., Hickson, I., Knights, C., et al. (2005). Targeting the DNA repair defect in BRCA mutant cells as a therapeutic strategy. Nature 434, 917-921.

Feng, L., Huang, J., and Chen, J. (2009). MERIT40 facilitates BRCA1 localization and DNA damage repair. Genes Dev 23, 719-728.

Fong, P.C., Boss, D.S., Yap, T.A., Tutt, A., Wu, P., Mergui-Roelvink, M., Mortimer, P., Swaisland, H., Lau, A., O'Connor, M.J., et al. (2009). Inhibition of poly(ADP-ribose) polymerase in tumors from
BRCA mutation carriers. N Engl J Med 361, 123-134.

Foray, N., Marot, D., Gabriel, A., Randrianarison, V., Carr, A.M., Perricaudet, M., Ashworth, A., and Jeggo, P. (2003). A subset of ATM- and ATR-dependent phosphorylation events requires the BRCA1 protein. EMBO J 22, 2860-2871.

Fu, Y.P., Yu, J.C., Cheng, T.C., Lou, M.A., Hsu, G.C., Wu, C.Y., Chen, S.T., Wu, H.S., Wu, P.E., and Shen, C.Y. (2003). Breast cancer risk associated with genotypic polymorphism of the nonhomologous end-joining genes: a multigenic study on cancer susceptibility. Cancer Res 63, 2440-2446.

Futreal, P.A., Liu, Q., Shattuck-Eidens, D., Cochran, C., Harshman, K., Tavtigian, S., Bennett, L.M., Haugen-Strano, A., Swensen, J., Miki, Y., et al. (1994). BRCA1 mutations in primary breast and ovarian carcinomas. Science 266, 120-122.

Greenberg, R.A., Sobhian, B., Pathania, S., Cantor, S.B., Nakatani, Y., and Livingston, D.M. (2006). Multifactorial contributions to an acute DNA damage response by BRCA1/BARD1-containing complexes. Genes Dev 20, 34 46.

Hall, J.M., Lee, M.K., Newman, B., Morrow, J.E., Anderson, L.A., Huey, B., and King, M.C. (1990). Linkage of early-onset familial breast cancer to chromosome 17q21. Science 250, 1684-1689.

Harfe, B.D., and Jinks-Robertson, S. (2000). DNA mismatch repair and genetic instability. Annu Rev Genet 34, 359-399.

Hartwell, L.H., and Kastan, M.B. (1994). Cell cycle control and cancer. Science 266, 1821-1828.

Hartwell, L.H., and Weinert, T.A. (1989). Checkpoints: controls that ensure the order of cell cycle events. Science 246, 629-634.

Huen, M.S., Grant, R., Manke, I., Minn, K., Yu, X., Yaffe, M.B., and Chen, J. (2007). RNF8 transduces the DNA-damage signal via histone ubiquitylation and checkpoint protein assembly. Cell 131, 901-914.

Jeggo, P.A. (1998). DNA breakage and repair. Adv Genet 38, 185-218.

Jeng, Y.M., Cai-Ng, S., Li, A., Furuta, S., Chew, H., Chen, P.L., Lee, E. Y., and Lee, W.H. (2007). Brca1 heterozygous mice have shortened life span and are prone to ovarian tumorigenesis with haploinsufficiency upon ionizing irradiation. Oncogene 26, 6160-6166.

Kim, H., Chen, J., and Yu, X. (2007a). Ubiquitin-binding protein RAP80 mediates BRCA1-dependent DNA damage response. Science 316, 1202-1205.

Kim, H., Huang, J., and Chen, J. (2007b). CCDC98 is a BRCA1BRCT domain-binding protein involved in the DNA damage response. Nat Struct Mol Biol 14, 710-715.

Kolas, N.K., Chapman, J.R., Nakada, S., Ylanko, J., Chahwan, R., Sweeney, F.D., Panier, S., Mendez, M., Wildenhain, J., Thomson, T.M., et al. (2007). Orchestration of the DNA-damage response by the RNF8 ubiquitin ligase. Science 318, 1637-1640.

Kuerbitz, S.J., Plunkett, B.S., Walsh, W.V., and Kastan, M.B. (1992). Wild-type p53 is a cell cycle checkpoint determinant following irradiation. Proc Natl Acad Sci U S A 89, 7491-7495.

Larner, J.M., Lee, H., and Hamlin, J.L. (1997). S phase damage sensing checkpoints in mammalian cells. Cancer Surv 29, 25-45.

Lee, J.H., and Paull, T.T. (2004). Direct activation of the ATM protein kinase by the Mre11/Rad50/Nbs1 complex. Science 304, 93-96.

Lee, J.H., and Paull, T.T. (2005). ATM activation by DNA doublestrand breaks through the Mre11-Rad50-Nbs1 complex. Science $308,551-554$. 
Lim, D.S., Kim, S.T., Xu, B., Maser, R.S., Lin, J., Petrini, J.H., and Kastan, M.B. (2000). ATM phosphorylates p95/nbs1 in an S-phase checkpoint pathway. Nature 404, 613-617.

Liu, X., Holstege, H., van der Gulden, H., Treur-Mulder, M., Zevenhoven, J., Velds, A., Kerkhoven, R.M., van Vliet, M.H., Wessels, L.F., Peterse, J.L., et al. (2007a). Somatic loss of BRCA1 and p53 in mice induces mammary tumors with features of human BRCA1-mutated basal-like breast cancer. Proc Natl Acad Sci U S A 104, 12111-12116.

Liu, Z., Wu, J., and Yu, X. (2007b). CCDC98 targets BRCA1 to DNA damage sites. Nat Struct Mol Biol 14, 716-720.

Lobrich, M., and Jeggo, P.A. (2007). The impact of a negligent G2/M checkpoint on genomic instability and cancer induction. Nat Rev Cancer 7, 861-869.

Mailand, N., Bekker-Jensen, S., Faustrup, H., Melander, F., Bartek, J., Lukas, C., and Lukas, J. (2007). RNF8 ubiquitylates histones at DNA double-strand breaks and promotes assembly of repair proteins. Cell 131, 887-900.

Mak, T.W., Hakem, A., McPherson, J.P., Shehabeldin, A., Zablocki, E., Migon, E., Duncan, G.S., Bouchard, D., Wakeham, A., Cheung, A., et al. (2000). Brcal required for T cell lineage development but not TCR loci rearrangement. Nat Immunol 1, 77-82.

Manke, I.A., Lowery, D.M., Nguyen, A., and Yaffe, M.B. (2003). BRCT repeats as phosphopeptide-binding modules involved in protein targeting. Science 302, 636-639.

McCarthy, A., Savage, K., Gabriel, A., Naceur, C., Reis-Filho, J.S., and Ashworth, A. (2007). A mouse model of basal-like breast carcinoma with metaplastic elements. J Pathol 211, 389-398.

Miki, Y., Swensen, J., Shattuck-Eidens, D., Futreal, P.A., Harshman, K., Tavtigian, S., Liu, Q., Cochran, C., Bennett, L.M., Ding, W., et al. (1994). A strong candidate for the breast and ovarian cancer susceptibility gene BRCA1. Science $266,66-71$.

Monteiro, A.N., August, A., and Hanafusa, H. (1996). Evidence for a transcriptional activation function of BRCA1 C-terminal region. Proc Natl Acad Sci U S A 93, 13595-13599.

Moynahan, M.E., Chiu, J.W., Koller, B.H., and Jasin, M. (1999). Brca1 controls homology-directed DNA repair. Mol Cell 4, 511-518.

Murakami, T., and Kawasaki, T. (1975). [Postgastrectomy small intestine adhesions]. Rinsho Hoshasen 20, 939-943.

O'Connell, M.J., Raleigh, J.M., Verkade, H.M., and Nurse, P. (1997). Chk1 is a wee1 kinase in the G2 DNA damage checkpoint inhibiting cdc2 by Y15 phosphorylation. EMBO J 16, 545-554.

O'Connell, M.J., Walworth, N.C., and Carr, A.M. (2000). The G2phase DNA-damage checkpoint. Trends Cell Biol 10, 296-303.

Painter, R.B. (1981). Radioresistant DNA synthesis: an intrinsic feature of ataxia telangiectasia. Mutat Res 84, 183-190.

Panier, S., and Durocher, D. (2009). Regulatory ubiquitylation in response to DNA double-strand breaks. DNA Repair (Amst) 8, 436-443.

Paull, T.T., Cortez, D., Bowers, B., Elledge, S.J., and Gellert, M. (2001). Direct DNA binding by Brca1. Proc Natl Acad Sci U S A 98, 6086-6091.

Reed, S.I., Bailly, E., Dulic, V., Hengst, L., Resnitzky, D., and Slingerland, J. (1994). G1 control in mammalian cells. J Cell Sci Suppl 18, 69-73.

Rhind, N., Furnari, B., and Russell, P. (1997). Cdc2 tyrosine phosphorylation is required for the DNA damage checkpoint in fission yeast. Genes Dev 11, 504-511.
Rodriguez, M., Yu, X., Chen, J., and Songyang, Z. (2003). Phosphopeptide binding specificities of BRCA1 $\mathrm{COOH}$-terminal (BRCT) domains. J Biol Chem 278, 52914-52918.

Scully, R., Chen, J., Ochs, R.L., Keegan, K., Hoekstra, M., Feunteun, J., and Livingston, D.M. (1997a). Dynamic changes of BRCA1 subnuclear location and phosphorylation state are initiated by DNA damage. Cell 90, 425-435.

Scully, R., Chen, J., Plug, A., Xiao, Y., Weaver, D., Feunteun, J., Ashley, T., and Livingston, D.M. (1997b). Association of BRCA1 with Rad51 in mitotic and meiotic cells. Cell 88, 265-275.

Scully, R., Ganesan, S., Brown, M., De Caprio, J.A., Cannistra, S.A., Feunteun, J., Schnitt, S., and Livingston, D.M. (1996). Location of BRCA1 in human breast and ovarian cancer cells. Science 272 , 123-126.

Scully, R., Ganesan, S., Vlasakova, K., Chen, J., Socolovsky, M., and Livingston, D.M. (1999). Genetic analysis of BRCA1 function in a defined tumor cell line. Mol Cell 4, 1093-1099.

Shakya, R., Szabolcs, M., McCarthy, E., Ospina, E., Basso, K., Nandula, S., Murty, V., Baer, R., and Ludwig, T. (2008). The basallike mammary carcinomas induced by Brca1 or Bard1 inactivation implicate the BRCA1/BARD1 heterodimer in tumor suppression. Proc Natl Acad Sci U S A 105, 7040-7045.

Shao, G., Patterson-Fortin, J., Messick, T.E., Feng, D., Shanbhag, N., Wang, Y., and Greenberg, R.A. (2009). MERIT40 controls BRCA1Rap80 complex integrity and recruitment to DNA double-strand breaks. Genes Dev 23, 740-754.

Shorrocks, J., Tobi, S.E., Latham, H., Peacock, J.H., Eeles, R., Eccles, D., and McMillan, T.J. (2004). Primary fibroblasts from BRCA1 heterozygotes display an abnormal G1/S cell cycle checkpoint following UVA irradiation but show normal levels of micronuclei following oxidative stress or mitomycin $C$ treatment. Int J Radiat Oncol Biol Phys 58, 470-478.

Snouwaert, J.N., Gowen, L.C., Latour, A.M., Mohn, A.R., Xiao, A., DiBiase, L., and Koller, B.H. (1999). BRCA1 deficient embryonic stem cells display a decreased homologous recombination frequency and an increased frequency of non-homologous recombination that is corrected by expression of a brca1 transgene. Oncogene 18, 7900-7907.

Sobhian, B., Shao, G., Lilli, D.R., Culhane, A.C., Moreau, L.A., Xia, B., Livingston, D.M., and Greenberg, R.A. (2007). RAP80 targets BRCA1 to specific ubiquitin structures at DNA damage sites. Science 316, 1198-1202.

Stucki, M., Clapperton, J.A., Mohammad, D., Yaffe, M.B., Smerdon, S.J., and Jackson, S.P. (2005). MDC1 directly binds phosphorylated histone $\mathrm{H} 2 \mathrm{AX}$ to regulate cellular responses to DNA doublestrand breaks. Cell 123, 1213-1226.

Sy, S.M., Huen, M.S., and Chen, J. (2009). PALB2 is an integral component of the BRCA complex required for homologous recombination repair. Proc Natl Acad Sci U S A 106, 7155-7160.

Venkitaraman, A.R. (2002). Cancer susceptibility and the functions of BRCA1 and BRCA2. Cell 108, 171-182.

Wang, B., Hurov, K., Hofmann, K., and Elledge, S.J. (2009). NBA1, a new player in the Brca1 A complex, is required for DNA damage resistance and checkpoint control. Genes Dev 23, 729-739.

Wang, B., Matsuoka, S., Ballif, B.A., Zhang, D., Smogorzewska, A., Gygi, S.P., and Elledge, S.J. (2007). Abraxas and RAP80 form a BRCA1 protein complex required for the DNA damage response. Science 316, 1194-1198. 
Wang, H., Zeng, Z.C., Bui, T.A., DiBiase, S.J., Qin, W., Xia, F., Powell, S.N., and lliakis, G. (2001). Nonhomologous end-joining of ionizing radiation-induced DNA double-stranded breaks in human tumor cells deficient in BRCA1 or BRCA2. Cancer Res 61, 270-277.

Wang, Y., Cortez, D., Yazdi, P., Neff, N., Elledge, S.J., and Qin, J. (2000). BASC, a super complex of BRCA1-associated proteins involved in the recognition and repair of aberrant DNA structures. Genes Dev 14, 927-939.

West, S.C. (2003). Molecular views of recombination proteins and their control. Nat Rev Mol Cell Biol 4, 435-445.

Williams, R.S., and Glover, J.N. (2003). Structural consequences of a cancer-causing BRCA1-BRCT missense mutation. J Biol Chem 278, 2630-2635.

Wu, J., Huen, M.S., Lu, L.Y., Ye, L., Dou, Y., Ljungman, M., Chen, J., and $\mathrm{Yu}, \mathrm{X}$. (2009). Histone ubiquitination associates with BRCA1dependent DNA damage response. Mol Cell Biol 29, 849-860.

Wu, X., Petrini, J.H., Heine, W.F., Weaver, D.T., Livingston, D.M., and Chen, J. (2000a). Independence of R/M/N focus formation and the presence of intact BRCA1. Science 289, 11.

Wu, X., Rathbun, G., Lane, W.S., Weaver, D.T., and Livingston, D.M. (2000b). Interactions of the Nijmegen breakage syndrome protein with ATM and BRCA1. Cold Spring Harb Symp Quant Biol 65, 535-545.

Xia, B., Sheng, Q., Nakanishi, K., Ohashi, A., Wu, J., Christ, N., Liu, X., Jasin, M., Couch, F.J., and Livingston, D.M. (2006). Control of BRCA2 cellular and clinical functions by a nuclear partner, PALB2. Mol Cell 22, 719-729.

Xu, B., Kim, S., and Kastan, M.B. (2001). Involvement of Brca1 in Sphase and $\mathrm{G}(2)$-phase checkpoints after ionizing irradiation. Mol Cell Biol 21, 3445-3450.

Xu, X., Wagner, K.U., Larson, D., Weaver, Z., Li, C., Ried, T., Hennighausen, L., Wynshaw-Boris, A., and Deng, C.X. (1999). Conditional mutation of Brca1 in mammary epithelial cells results in blunted ductal morphogenesis and tumour formation. Nat Genet 22, 37-43.
Yarden, R.I., Pardo-Reoyo, S., Sgagias, M., Cowan, K.H., and Brody, L.C. (2002). BRCA1 regulates the G2/M checkpoint by activating Chk1 kinase upon DNA damage. Nat Genet 30, 285-289.

Yazdi, P.T., Wang, Y., Zhao, S., Patel, N., Lee, E.Y., and Qin, J. (2002). SMC1 is a downstream effector in the ATM/NBS1 branch of the human S-phase checkpoint. Genes Dev 16, 571-582.

$\mathrm{Yu}, \mathrm{X}$., and Chen, J. (2004). DNA damage-induced cell cycle checkpoint control requires CtIP, a phosphorylation-dependent binding partner of BRCA1 C-terminal domains. Mol Cell Biol 24, 9478-9486.

Yu, X., Chini, C.C., He, M., Mer, G., and Chen, J. (2003). The BRCT domain is a phospho-protein binding domain. Science 302 , 639-642.

Zhang, F., Fan, Q., Ren, K., and Andreassen, P.R. (2009a). PALB2 functionally connects the breast cancer susceptibility proteins BRCA1 and BRCA2. Mol Cancer Res 7, 1110-1118.

Zhang, F., Ma, J., Wu, J., Ye, L., Cai, H., Xia, B., and Yu, X. (2009b). PALB2 links BRCA1 and BRCA2 in the DNA-damage response. Curr Biol 19, 524-529.

Zhao, G.Y., Sonoda, E., Barber, L.J., Oka, H., Murakawa, Y., Yamada, K., Ikura, T., Wang, X., Kobayashi, M., Yamamoto, K., et al. (2007). A critical role for the ubiquitin-conjugating enzyme Ubc13 in initiating homologous recombination. Mol Cell 25, 663-675.

Zhao, H., Watkins, J.L., and Piwnica-Worms, H. (2002). Disruption of the checkpoint kinase $1 /$ cell division cycle $25 \mathrm{~A}$ pathway abrogates ionizing radiation-induced $S$ and $\mathrm{G} 2$ checkpoints. Proc Natl Acad Sci U S A 99, 14795-14800.

Zhong, Q., Chen, C.F., Chen, P.L., and Lee, W.H. (2002). BRCA1 facilitates microhomology-mediated end joining of DNA double strand breaks. J Biol Chem 277, 28641-28647.

Zhong, Q., Chen, C.F., Li, S., Chen, Y., Wang, C.C., Xiao, J., Chen, P. L., Sharp, Z.D., and Lee, W.H. (1999). Association of BRCA1 with the hRad50-hMre11-p95 complex and the DNA damage response. Science 285, 747-750. 